\title{
Ronald Kay, nuestro contemporáneo
}

La figura de Ronald Kay es fundamental para pensar el arte, la poesía y la fotografía en Chile y la relación de estas disciplinas con los centros hegemónicos. La identificación de la imagen técnica como dispositivo particular que tensiona este vínculo, ofrece una reflexión de orden filosófica original en nuestro continente.

En su texto del 2007 “QQué es lo contemporáneo?” el filósofo italiano Giorgio Agamben afirma que los verdaderos contemporáneos son quienes no coinciden perfectamente con su tiempo, ni se ajustan cabalmente a sus demandas. Hay cierta desconexión, cierto anacronismo que los hace capaces de percibir y captar mejor su propia época, pero no su lado luminoso, sino que la oscuridad de su tiempo. El verdadero contemporáneo, según Agamben, es quien puede establecer una relación peculiar con el pasado, y citarlo. Así, la contemporaneidad estaría marcada por lo arcaico, de modo que la relación que se establece con el presente sería arqueológica. La cita al pasado en su versión benjaminiana - como catástrofe o como ruina- o en términos iconográficos -como supervivencia o rima visual- son una constante en Kay, tal como lo veremos en los trabajos que abordan su obra.

Kay nació en Hamburgo en 1941 y murió en Santiago el 2017, por lo que su vida estuvo marcada por la nomadía y los intercambios transatlánticos. Su primer viaje a Chile, en 1947, lo realizó en el contexto de la Segunda Guerra Mundial, de la que su familia escapó en el primer barco civil autorizado para cruzar el Atlántico. En 1960 estuvo un año en Inglaterra y entre 1968 y 1972 se radicó en Alemania, para realizar sus estudios de doctorado en la Universidad de Constanza. Poeta, teórico y artista visual, introdujo en el contexto de los años 70 en Chile la lectura de Walter Benjamin. A partir de 1972 formó parte del Departamento de Estudios Humanísticos de la Universidad de Chile, donde formó a numerosos artistas y escritores. En 1975 editó el único número de la revista Manuscritos, donde se publicó "El Quebrantahuesos", una intervención con recortes de periódicos realizada por Nicanor Parra, Alejandro 
Jodorowsky y Enrique Lihn en 1952, un hito fundamental para la producción poética y visual chilena. En 1979 publicó su poemario Variaciones ornamentales y en 1980 su ensayo seminal sobre fotografía y la obra de Eugenio Dittborn, Del espacio de acá. Señales para una mirada americana. En 1980 Kay se radicó en Alemania desde donde realizó proyectos vinculados con Chile: publicó La historia de la sensibilidad del etnógrafo Hubert Fichte y Psyche, con etnopoesía de Fichte y fotografías de Leonore Mau. Entre el 2000 y 2001 publicó Los inéditos de las década de los 60, compuesto por los poemarios Punto de fuga y Deep Freeze, y las glosas de Circuito cerrado. El 2009 volvió a radicarse en Chile.

Su trabajo no estuvo exento de colaboraciones y proyectos colectivos que incluían la visibilización del trabajo de otros artistas e intelectuales, prácticas que siguieron vigentes hasta el final de sus días: el 2012, por ejemplo, editó el libro póstumo de poesía visual de Juan Luis Martínez, Aproximación del principio de incertidumbre a un proyecto poético y en julio de 2017 dictó la conferencia "Monumento a Pedro Aguirre Cerda" sobre la obra del escultor Lorenzo Berg.

La estrategia ensayística de Kay, permite una apertura y libertad en la teorización que muchas veces la tradición académica restringe. Las ideas que se desprenden de sus ensayos permanecen vigentes y nos entregan herramientas para situar críticamente nuestra producción cultural en el contexto latinoamericano.

Tras su muerte, ocurrida el 21 de septiembre del 2017, el Instituto de Estética organizó un coloquio homenaje a principios de noviembre de ese año. En esa ocasión se reunieron una serie de textos incluidos en este número, al que se sumaron las colaboraciones de otros investigadores que se encontraban trabajando la obra de Kay. El resultado de estas contribuciones dan forma a este dossier.

"Escuchar a Kay" es la transcripción de un par de sesiones de trabajo que realizó Ronald Kay en el Goethe Institut de Santiago de Chile en 1981. La artista chilena Luz Donoso participó de estas conferencias grabándolas, creando, de este modo, un valioso documento. Esta transcripción es de gran relevancia, ya que Kay se dedica a explicar, básicamente, el clásico texto de Walter Benjamin "La obra de arte en la época de su reproductibilidad técnica”, ensayo desconocido para la época en nuestro espacio cultural. Nos recuerdan los autores de esta colaboración, Paulina Varas y Francisco Godoy, que es Kay quien introduce a este filósofo en Chile a través de sus propias traducciones. De este modo, este artículo transmite la vitalidad de las reflexiones que se dieron en la experiencia de lectura directa.

En "La referencialidad americana" José Pablo Concha parte de una de las tesis centrales de Kay en Del espacio de acá, que reflexiona sobre la temporalidad de la visualidad 
americana a partir la llegada del aparato fotográfico al continente. Concha aborda el problema de la temporalidad estableciendo una distinción filosófica entre el tiempo técnico (instante) y el tiempo existencial (duración), y postula que la virtualidad que hace posible la fotografía, pone en coexistencia el tiempo y el espacio, que colisionan provocando -en palabras de Kay- una "catástrofe cósmica". Según Concha, la única referencialidad posible en fotografía, es el propio dispositivo, que satura de significado al objeto frente a la cámara.

Ana María Risco propone en "En cámara lenta. Repensando la poética de R. Kay sobre fotografía y «mirada americana»" una revisión crítica de la tesis fundamental de Kay respecto del fallo de la tradición pictórica en Chile y al rol que le cabe a la fotografía en la configuración de esta "mirada americana" sobre los sujetos y paisaje de este territorio. Un aspecto central de esta tesis es el concepto de "discronía" que implica el registro fotográfico en el territorio americano en el siglo XIX, premoderno, prefotográfico, de un dispositivo que encarna, precisamente lo moderno y lo industrial. Risco observa detenidamente lo que denomina "la parte más discutible de la tesis de Kay", argumentando que el autor habría considerado a la visualidad americana como infrapictórica, eludiendo la tradición visual colonial.

Paz López en su artículo "Ronald Kay y Eugenio Dittborn. La imagen de la Pietá, la Pietá como imagen" se propone interrogar la relación entre imagen, historia y memoria en el trabajo de Kay, particularmente a partir de su abordaje de la obra de Eugenio Dittborn. Según López, Kay emparenta el trabajo pictórico de Dittborn con la trama temporal de la imagen fotográfica, que pone en entredicho la idea del presente y la presencia como modelo temporal privilegiado. Del mismo modo, López vincula la noción de "rima visual" de Kay con el trabajo de Aby Warburg, quien piensa los tiempos de la imagen a partir de las nociones de "supervivencia" (nachleben) y "fórmulas expresivas" (pathosformel). La autora afirma que la Pietá se convierte en cifra de la noción de "rima visual" en Dittborn.

“(De)Construcción del arte a partir de Ronald Kay” es el artículo en que Elixabete Ansa analiza la actualidad, para la crítica de arte en Chile, del gesto teórico que significa el ensayo Del espacio de acá. Señales para una mirada americana. Los conceptos de "Constructivismo" y de "Deconstrucción" serán vistos como estrategias implícitas en el método crítico de Ronald Kay. La actualización de estos conceptos se constituiría en un aporte relevante, según Ansa, precisamente, para la historiografía del arte chileno, lo que la autora pone a prueba en artistas como Isamitt, Vergara Grez y Dittborn.

"Despojos de psique. Trauma, inscripción y archivo en Tentativa Artaud de R. Kay" de Francisco Vega postula que Tentativa Artaud, una acción/instalación realizada por Kay en 1974 a partir de su seminario sobre el actor y dramaturgo francés en el 
departamento de Estudios Humanísticos de la Universidad de Chile, es fundamental como obra en su forma de entretejer aspectos artísticos, teóricos y políticos. En ella participaron la artista visual Catalina Parra, el poeta Raúl Zurita, Eugenio García y el novelista Juan Balbontín, y tiene influjos de Fluxus, Vostell, Beuys y Duchamp, entre otros. La obra plantea interrogantes en torno a las nociones de archivo, virtualidad y diferimiento, que según Vega, la crítica de arte chilena no ha estudiado en profundidad, pero que en la actualidad, resultan ineludibles para pensar tanto la memoria de la política, como las políticas de la memoria.

Valeria de los Ríos en su artículo "Medialidad, movimiento y paradoja temporal en la escritura de Ronald Kay" explora lo que se ha llamado "el gesto fundacional" que Kay realiza en la revista Manuscritos, concerniente, precisamente, a la importancia asignada por el autor a la medialidad, lo que sería una estrategia que rompería con la tradición de la estética moderna. De los Ríos observa, además, cuidadosamente la presencia de la fotografía, el cine y la televisión, tanto en su obra crítica Del espacio de acá y Circuito cerrado; como en la poética, Variaciones ornamentales y Deep Freeze. Es interesante el uso que Kay le da al recurso medial como posibilidad metafórica en la caracterización existencial de sujetos referidos, pero además, como posibilidad de resignificación de las dimensiones espaciales y temporales del acontecimiento.

José Pablo Concha y Valeria de los Ríos Editores 